\title{
Educação ambiental numa perspectiva dialógico-problematizadora e o XI Festival Internacional de Cinema e Vídeo Ambiental (FICA)
}

\section{Environmental Education in a dialogical problem-solving perspective and the Xlth International Environmental Film and Video Festival (FICA)}

Carlos Hiroo Saito ${ }^{1}$ Kelley Marques ${ }^{2}$

\begin{abstract}
RESUMO: O texto parte da experiência de um mini curso de educação ambiental realizado no âmbito do XI Festival Internacional de Cinema e Video Ambiental (FICA), em junho de 2009, na cidade histórica de Goiás - GO, em que se abordou as bases teóricas que guiaram a produção de um conjunto articulado de material didático impresso (composto de portfólios com fotos e textos, um livro do professor e um jogo educativo de tabuleiro), produzido para o Projeto de Conservação e Utilização Sustentável da Diversidade Biológica Brasileira (PROBIO), do Ministério do Meio Ambiente no ano de 2005-2006. A partir das bases teóricas explicitadas, vinculadas à concepção dialógico-problematizadora de Paulo Freire, articuladas às idéias de investigação-ação, empowerment, analisa-se a contribuição educacional da mostra específica do FICA Animado - Mostra Infantil, voltada para o público infantil diante desse arcabouço teórico. A falta de sintonia entre os filmes e vídeos apresentados no FICA Animado e os fundamentos de uma educação ambiental filiada à teoria crítica, levam à necessidade de apresentar recomendações específicas para que uma nova edição do FICA Animado tenha um papel mais educativo, cumprindo efetivamente o objetivo para o qual foi criado.
\end{abstract}

Palavras-chave: educação ambiental; Festival Internacional de Cinema e Video Ambiental; Paulo Freire; material didático; conservação da biodiversidade.

ABSTRACT: The article comments the experience of a short course about environmental education held in the XIth International Environmental Film and Video Festival (FICA), in June 2009, em the historical town of Goiás, State of Goias. There, it was analyzed the theoretical basis which guided the development of an articulated set of didactic materials (composed by portraits, a book for the teachers and an board game) produced for the Brazilian Ministry of Environment/PROBIO - Project for the Conservation and Sustainable Use of Brazilian Biological Diversity in 2006. From this theoretical basis, supported on the Paulo Freire's dialogical problem-solving educational concept, integrated to action research and empowerment conceptions, it was analyzed the educational contribution of an specific exhibition of films and videos for children called "Animated FICA". The lack of accordance between the films and video showed in FICAAnimado and the theoretical basis of a critical environmental education claimed to the necessity to present some specific recommendation to make the next edition of FICA Animado a more children education friendly exhibition. 
Keywords: environmental education; International Environmental Film and Video Festival; Paulo Freire; didactic material; biodiversity conservation.

\section{INTRODUÇÃO}

O XI Festival Internacional de Cinema e Video Ambiental - FICA, realizado na cidade de Goiás - GO, de 16 a 21 de junho de 2009, contou na sua programação com um mini curso de educação ambiental intitulado "Educação ambiental: Ensinando e aprendendo com a natureza". Este mini curso teve seu foco centrado no material didático do Projeto de Conservação e Utilização Sustentável da Diversidade Biológica Brasileira - PROBIO/ MMA, produzido sob a coordenação do Departamento de Ecologia da Universidade de Brasília em 2006, com recursos do PROBIO/Ministério do Meio Ambiente/BIRD-Global Environment Facility/CNPq, tendo contado com a participação das instituições parceiras nos UFPE, UFMT, UFSM, CDCC/USP - Campus São Carlos, Projeto Lagoa Mirim/IBAMA/ CSR, AQUASIS, Instituto Baleia Jubarte, UNEB - Campus Jacobina e EMBRAPA Amazônia Oriental. O material didático, aqui denominado Probio-EA, compreende um conjunto articulado de material didático impresso de educação ambiental (composto de portfólios com fotos e textos, um livro do professor e um jogo educativo de tabuleiro) a respeito da conservação da diversidade biológica brasileira em todos os seus biomas. Neste material, disponível em <http://www.unb.br/ib/ecl/eaprobio>, os biomas brasileiros, as espécies da fauna brasileira ameaçadas de extinção (constantes da lista oficial), a problemática da fragmentação de ecossistemas e das espécies exóticas invasoras e a importância das Unidades de Conservação da Natureza, são tratados de forma articulada, correspondendo aos temas considerados prioritários pelo PROBIO/MMA.

A própria realização do mini curso e, numa perspectiva histórica mais ampla, a própria realização do FICA, se inserem no contexto de valorização da temática ambiental de modo geral, e de forma específica, da Conservação da Biodiversidade, retratado em Saito e Almeida (2006), e que levou o ano de 2010 a ganhar o título de Ano Internacional da Biodiversidade.

O objetivo deste trabalho é analisar a relação entre a abordagem de educação ambiental realizada neste mini curso do XI FICA, e o próprio FICA e suas mostras de cinema e vídeo, especialmente a mostra infantil, novidade nessa edição do festival, denominada FICA ANIMADO.

\section{O mini curso}

No mini curso, de 9 horas de duração, dividido em três períodos de 3 horas cada, adotou-se os seguintes procedimentos metodológicos: 1) explicitar a matriz epistemológica e a concepção didático-metodológica do material didático Probio-EA; 2) problematizar com os participantes os Biomas Brasileiros (Amazônia, Ambientes Costeiros e Marinhos, Caatinga, Cerrado, Campos Sulinos ou Pampas, Mata Atlântica e Pantanal) e Temas (Biomas Brasileiros, Biodiversidade Brasileira, Espécies da Fauna Brasileira Ameaçadas de Extinção, Espécies Exóticas Invasoras, Fragmentação de Ecossistemas e Unidades de Conservação da Natureza); 3) implementar com os participantes as sugestões de utilização dos portfólios em sala de aula; 4) jogar com os participantes o jogo educativo de tabuleiro; 5) avaliar com os participantes os materiais didáticos; e 6) avaliar com os participantes a contribuição da matriz epistemológica e a concepção didático-metodológica do material didático Probio-EA na análise e compreensão das mostras de cinema e vídeo do XI FICA, especialmente a mostra do FICA ANIMADO.

Primeiramente, buscou-se explicitar a valorização das perspectivas crítica e emancipatória pelo material didático Probio-EA (SAITO et al., 2008). Estas perspectivas 
estariam presentes de alguma forma na própria Política Nacional de Educação Ambiental, estabelecida pela Lei 9.795/1999 como desafios contemporâneos para a educação ambiental no Brasil, tendo em vista o disposto no Artigo 5o, Inciso III ("o estímulo e o fortalecimento de uma consciência crítica sobre a problemática ambiental e social") e no Artigo 5o, Inciso V ("construção de uma sociedade ambientalmente equilibrada, fundamentada nos princípios da liberdade, igualdade, solidariedade, democracia, justiça social, responsabilidade e sustentabilidade"), conforme Saito (2002).

Assim, o manuseio inicialmente livre dos portfólios pelos cursistas revelou a eles a organização dos mesmos num padrão regular pareado de conflitos socioambientais e ações positivas, o primeiro correspondendo aos problemas e o segundo às respectivas soluções. Sinalizou-se assim que o material promove um "incentivo à participação individual e coletiva, permanente e responsável, na preservação do equilíbrio do meio ambiente, entendendo-se a defesa da qualidade ambiental como um valor inseparável do exercício da cidadania", em conformidade ao prescrito na Política Nacional de Educação Ambiental, artigo 5o, IV, da Lei 9.795/1999.

Na mesma lei, no Artigo 3o, VI, é dito que cabe à sociedade, como um todo, manter atenção permanente à formação de valores, atitudes e habilidades que propiciem a atuação individual e coletiva voltada para a prevenção, a identificação e a solução de problemas ambientais. O conhecimento assume grande valor neste momento, defendendo-se porém o "desenvolvimento de uma compreensão integrada do meio ambiente, em suas múltiplas e complexas relações, envolvendo aspectos ecológicos, psicológicos, legais, políticos, sociais, econômicos, científicos, culturais e éticos" (artigo 5o, inciso I), combatendo uma visão unilateral do meio ambiente e restrita a uma única área do conhecimento.

Portanto, no mini curso, procurou-se o tempo todo estabelecer um nexo relacional entre o material didático Probio-EA e a Política Nacional de Educação Ambiental. Isto para que os cursistas compreendessem que uma Lei, no caso a Lei 9.795/1999, não se configurasse apenas como um mero documento formal, mas que fosse capaz de inspirar e guiar efetivamente uma ação pública, e que um material didático não tem sua produção guiada por caprichos estéticos aleatórios, mas que pode e deve incorporar desde a sua concepção até sua materialização, em cada detalhe, princípios e diretrizes de uma política educacional e ambiental estabelecida. E que, portanto, não é produto do acaso mas de uma ação intencional.

\section{O binômio conflito socioambiental-ação positiva e a abordagem didático- metodológica segundo a pedagogia dialógico- problematizadora}

Queremos chamar a atenção para o binômio conflito socioambiental-ação positiva presente no material Probio-EA e sua relação com a abordagem didático-metodológica segundo a pedagogia dialógico-problematizadora, e desta com o FICAAnimado. Incluímos nessa reflexão epistemológica a análise de recursos fundamentais voltados para a neurodidática, consistindo em subsídios didáticos-metodológicos para o resultado da aprendizagem significativa.

Os conflitos socioambientais correspondem àquelas situações-problema freireanamente falando (FREIRE, 1987) que correspondem aos conflitos na esfera social que originam impactos ambientais sobre a biodiversidade. Desta forma, os portfólios tornam explícitas tanto a origem como a natureza dos conflitos, cujas soluções, orientadas e apoiadas nos conhecimentos científico-tecnológico e tradicional, correspondem a uma ação positiva, como solução historicamente viável na perspectiva da justiça social e sustentabilidade socioambiental (SAITO et al., 2008). Explicita-se assim a consistência epistemológica e metodológica, no uso da comunicação e linguagem voltada para a mudança de comportamento na educação. Isto porque, no aspecto neurodidático, focamos a intervenção pela diversidade de teorias de aprendizagem, com estímulos 
inicialmente comportamentais, continuando com estímulos mediatizados de forma cognitiva e estabelecendo o resultado parcial com intervenções didáticas sócio-interativas, assim designando um espaço de conhecimento pela metacognição-metaconhecimento (FONSECA, 2009; RELVAS, 2009; PORTILHO, 2009)

Portanto, para melhor compreender a base teórica do material didático, faz-se necessário retomar um pouco mais do referencial teórico da pedagogia problematizadora, conforme já realizado em Saito et al. (2008).

Para Freire (1967, 1970 e 1987), o ser humano tem papel ativo em sua realidade, produzindo, ao viver seu dia-a-dia, o que chama de cultura no seu mundo (produto da interação sociedade-natureza). No entanto, embora viva e produza cultura e transforme o mundo, muitas vezes não tem compreensão desse processo e de seu papel, e menos ainda das implicações para o meio ambiente dessas ações. Mesmo quando há uma percepção preliminar da degradação do meio ambiente causada pelas ações humanas e os impactos negativos decorrentes dessa degradação, muitas vezes falta-lhes uma compreensão clara sobre a relação de causa e da cadeia de conseqüências, sobre o modo de reparação do dano ou mesmo de sua prevenção. Ou seja, há um hiato a ser transposto entre a percepção vivida (imediata) e a consciência real. Quando esse hiato é efetivamente transposto, produz-se um conhecimento sustentável numa mescla entre conhecimento novo e conhecimento antigo, transformando-se numa formatação sócio-interativa do uso da zona de desenvolvimento proximal (RELVAS, 2009)

Este hiato deve ser transposto pela promoção de uma consciência socioambiental científico-tecnologicamente embasada, pela promoção da interação entre educador educando, mediada pelo conhecimento científico-tecnológico e contextualizada pela realidade concreta a ser compreendida e transformada. O conceito de mediação científicotecnológica volta a ser destacado a partir da centralidade explicitada em Santos et al. (2005) para promover processos participativos na gestão ambiental.

Em Saito et al. (2008), já foi citado como exemplo do papel mediador do conhecimento científico-tecnológico presente no material didático Probio-EA a morte dos golfinhos-dedentes-rugosos (Steno bredanensis) provocada pela presença de lixo plástico nas praias (situação-problema, ou conflito socioambiental) e a respectiva ação positiva (ou solução) baseado na gestão de resíduos sólidos. Além desse exemplo, pode-se mencionar a morte dos albatrozes-errante (Diomedea exulans), capturados acidentalmente em pesca com espinhel e a respectiva solução, baseada na incorporação de técnicas de evitação do acidente, como o "toriline", largada noturna ou tingimento de iscas, todas baseadas no conhecimento científico do comportamento dessas aves.

Esses dois exemplos lidam mais com situações em que os agentes de degradação são indivíduos comuns em suas práticas cotidianas de vida.

Também no material se faz presente exemplos em que os agentes de degradação (ou potencial degradação) podem ser reconhecidos como entes públicos ou entes privados, nãopersonalizados em indivíduos, mas representativos de interesses políticos e econômicos.

Por exemplo, o projeto de lei encaminhado pelo executivo estadual do Mato Grosso do Sul à Assembléia Legislativa, que altera a lei atual proibitiva passando, assim, a permitir a instalação de agroindústrias de cana-de-açúcar e seus derivados na Bacia do Alto Paraguai, onde está inserido o Pantanal. A compreensão do embate travado com a sociedade civil mobilizada contra essa iniciativa passa pela mediação científico-tecnológica, em que o domínio do conceito de bacia hidrográfica ocupa lugar importante na desmitificação dos argumentos de que a iniciativa não poluiria de forma alguma o Pantanal pelo simples fato das indústrias se localizarem fora dos domínios da área de inundação (escondendo o fato de que se localizariam nas partes altas, cabeceiras dos rios que drenam para o Pantanal). 
Esta problematização também se faz presente quando se aborda o tema Fragmentação de Ecossistemas no Bioma Campos Sulinos e reflete-se a respeito da conversão dos pampas em monoculturas de eucalipto sob a insígnia de uma idéia de Poupança Florestal, denunciando o desvirtuamento do debate sobre a importância da integridade daquele tipo de ecossistema original, ou sobre as possíveis alternativas econômicas para a sustentabilidade do bioma.

Por isso, partir dos conflitos socioambientais significa organizar objetos de estudo que abordem universos temáticos específicos (por exemplo, conflitos socioambientais em torno da problematização temática fragmentação de ecossistemas no bioma campos sulinos), em que situações existenciais típicas ${ }^{3}$ são identificadas para serem problematizadas ("por que a vegetação dos campos da metade sul estão sendo convertidos em florestas de eucalipto?") conforme Saito et al. (2008).

Neste material didático, dando seqüência à opção teórica em Paulo Freire, procedeu-se à codificação ${ }^{4}$ e decodificação, de forma que as situações-conflito (conflitos socioambientais) fossem apresentadas como desafios em que a percepção e apreensão da natureza do conflito socioambiental requeria um ir e vir entre a foto e o texto, que então passaria a ser decodificada (assimilada, compreendidas, através de interações dialógicas) pelos alunos, com a mediação dos professores e dos conhecimentos científico-tecnológicos e tradicionais (SAITO et al., 2008).

O ponto final desse processo de decodificação é a internalização das ações positivas, sua plena compreensão e assimilação, como possibilidade real de intervenção historicamente viável na realidade, e que pode ser transposta para outras realidades que vivem situações de conflitos similares. Assim, o material didático estaria propiciando um estreitamento de vínculos nas comunidades, promovendo um enpowerment das lutas socioambientais em prol da resolução dos conflitos e dinamizando os movimentos socioambientais.

Além disso, o conhecimento e compreensão da viabilidade científico-tecnológica e socialmente dada da solução (ação positiva) representa o fortalecimento e disseminação da esperança num novo amanhã, o reconhecimento da capacidade de sermos sujeitos ativos da história, e apontar alternativas sustentáveis para a humanidade.

A estrutura de produção do conhecimento, principalmente ambiental num aspecto sistêmico, deve desenvolver um elo entre a epistemologia "professada" e a epistemologia "adotada", principalmente nas escolhas teóricas dos professores (BECKER, 1995). Isto porque a aproximação destes evidenciam a consistência neurodidática, possível de estabelecer resultados cognitivos essenciais para uma estrutura de aprendizagem significativa, como definição de competências mínimas e habilidades específicas (linguagem, memória, percepção, organização lógica, afetividade, seleção de estímulos, mudança de comportamento-habitos).

Esse é um aspecto crucial do ponto de vista pedagógico, tendo em vista que não basta ser educativo pela via da denúncia, da apresentação dos conflitos socioambientais. É preciso educar para a busca pró-ativa da solução dos conflitos, é preciso instrumentalizar para "a atuação individual e coletiva voltada para a prevenção, a identificação e a solução de problemas ambientais" (Lei 9.795/1999, Artigo 3o, VI). Enfim, é preciso por em prática uma pedagogia da esperança (FREIRE, 2003).

O mini curso de educação ambiental, o material didático Probio-EA e a mostra de cinema e video do XI FICA

$\mathrm{Na} \mathrm{XI}$ edição do FICA pela primeira vez introduziu-se uma mostra especial, dirigida ao público infantil, chamado FICAAnimado, com a expectativa de aposta nas crianças para conscientização dos adultos de hoje e do futuro. O primeiro FICA Animado trouxe onze curta metragens, nacionais e estrangeiros, todos com temática ambiental. 
Portanto, as repercussões dessa mostra especial do FICA Animado entre os participantes do mini curso ganham lugar especial em termos de análise no presente trabalho, ressaltando que as discussões travadas no mini curso decorrem do referencial teórico adotado no material didático Probio-EA.

O primeiro dos filmes ("Cattum", de Paulo Miranda) conta a história de um gato abandonado na rua e que, depois de causar muitos transtornos no trânsito urbano e em função disso, ser reiteradamente agredido por pedestres e motoristas, tem um final em que o filme sugestiona o expectador de que teria virado "churrasquinho" de gato.

Outro filme, "He/Who laughs last..." ( Miroslav Jovic ) conta a história de duas árvores na floresta, uma magra e outra gorda. Na história, a árvore gorda vive rindo da árvore magra, que se sente constrangida e diminuída. Quando chegam os madeireiros, equipados com machado e motosserra, as árvores temem pela sua existência, e os madeireiros optam por derrubar a árvore gorda e transformá-la em toras que são carregadas no caminhão, enquanto a árvore magra é poupada. A seqüência de emoções vivida pela árvore, de temor, alívio e então de deboche e riso pelo fato de ter sido poupada e a sua rival não, é bem marcante. O título do filme, traduzido como "Quem ri por último...." é sugestivo, mas não para aí. O motorista do caminhão, ao perceber a árvore rindo, resolve jogar uma ponta de cigarro na árvore, que então pega fogo. As outras árvores da floresta, então, passam a rir da árvore magra, que estava rindo do trágico destino da sua rival, e agora sofria o infortúnio do fogo, sendo castigada por ter debochado da tragédia alheia. No entanto, a árvore em chama se sacode tentando debelar o fogo e termina por espalhar as chamas para todos os lados, incendiando toda a floresta, encerrando o filme.

Do ponto de vista educativo, são dois exemplos bem contundentes de frágil contribuição à formação de valores e posturas/hábitos saudáveis nas crianças, não contribuindo, ainda, para mostrar alternativas tanto ao abandono de animais domésticos como ao desmatamento, nem mesmo evidenciando cognitivamente reflexões além da imagem, deixando a desejar no aspecto da comunicação para formação de subsídios para a meta cognição. Neste aspecto a neurodidática seria um caminho epistemológico de resultados possíveis de mudança de aprendizagens, passando daquelas meramente reprodutivistas para aprendizagens sóciocríticas, principalmente na análise de diversidade de conhecimentos e não meramente na apresentação de respostas prontas, inibindo a construção da postura emancipatória do meta conhecimento de forma autodidata.

É certo que pode-se levantar o argumento da liberdade do cineasta de desabafar, extravasar seus sentimentos de condenação à degradação ambiental, ou simplesmente retratar como vê, de forma trágica, e exacerbando o lado perverso, buscar uma tomada de consciência no sentido contrário, mas o uso da imagem pode ser utilizado como uso de estímulo direto (mera reprodução de sentidos) e principalmente como estímulos mediatizados (produção de metaconhecimento-autodidata).

No entanto, pedagogicamente falando, faz-se necessário apontar saídas, e não apenas apontar problemas. Imprescindível então envolver as inovações da ciências da aprendizagem, na construção de valores bioéticos, diante da estruturação de seres humanos cognitivamente pensáveis e metodologicamente seguros, para que de suas sóciointerações possam influenciar outros a hábitos e valores mais saudáveis, comprometidos com a sustentabilidade socioambiental (MARQUES, 2009)

Esse foi o centro do material didático Probio-EA enfatizando no mini curso, a pedagogia da esperança e da instrumentalização científico-tecnológica para a solução dos conflitos socioambientais.

Um outro filme, "Calango Lengo - Morte e Vida Sem Ver Água", bastante aplaudido pelas crianças devido a beleza plástica, boa sonoplastia e carisma do personagem central, também merece comentários à luz do material didático Probio-EA. 
No filme, o calango chamado Lengo, nordestino, vive o drama das conseqüências da seca, caracterizado pela falta de comida para pôr no prato. O filme ganha animação a partir do momento em que Lengo tem que fugir da morte, caracterizada como uma caveira segurando uma foice, tentando ceifar a vida do calango. O filme animado explora a cultura popular e soluciona o drama ao seu final, apresentando o calango sendo salvo de ser alcançado pela morte pela intervenção de "Nossa Senhora". Em que pese o fator cultural, e sua identificação pelos expectadores, do ponto de vista educativo, o filme perde a oportunidade de apresentar uma solução científica e tecnologicamente viável e que se encontra em plena execução no semi-árido: o Programa Um Milhão de Cisternas Rurais, desenvolvido pela Articulação no Semi-Árido Brasileiro (Asa).

Conforme retratado no portfólio <Tema: Biomas Brasileiros, Bioma: Caatinga>, "Além de construir as cisternas com pedreiros das próprias comunidades do Bioma Caatinga e em locais identificados por elas, o programa ensina noções de ecologia, armazenamento e tratamento de água e cidadania. As escolas também podem ajudar na conscientização, como vem ocorrendo na escola rural Ouricuri, PE, onde um projeto de educação ambiental mostrou aos alunos da 4a série as potencialidades da vida no Bioma Caatinga, entre elas a captação e uso da água da chuva por meio de cisternas, e o plantio de alimentos para o ser humano e os animais sem prejudicar o meio ambiente.".

\section{CONSIDERAÇÕES FINAIS}

Em que pese a iniciativa louvável de promover a mostra especial FICA Animado, destinado ao público infantil, recomenda-se que numa próxima edição dessa mostra especial, tenha-se em mente uma maior preocupação com o aspecto educativo dos filmes, fundamentando a iniciativa extremamente rica com intervenções didáticas de âmbito significativo para a aprendizagem.

Nessa perspectiva, recomenda-se que os cineastas sejam orientados para, sem abrir mão de sua criatividade e liberdade, e principalmente, fazendo uso delas, produzirem e inscreverem no FICA filmes animados verdadeiramente educativos, capazes de aproveitar da linguagem animada que tanto cativa o público infantil para conscientizá-los, a partir da problematização de conflitos socioambientais próximos do seu cotidiano. Esperamos com isso que esses cineastas sejam capazes de mostrar as soluções historicamente viáveis, as que efetivamente já estão sendo implementadas, e a compreensão de sua operatividade, de forma a realizar uma mostra de esperança, vinculando a consistência da imagem e da comunicação com um aspecto didático-metodológico na produção de conhecimento capazes de construir posturas e valores para a diversidade cultural.

Novamente, reforçamos a concepção de que a problematização é potencializadora para gerar e sustentar o processo educacional, através do reconhecimento do problema local, o interesse, o debate e a busca de sua solução, de forma conjunta, compreendendo o que existe de regular, comum. A compreensão dessa regularidade deve contribuir para que o aprendido possa ser lembrado sempre que o problema surgir, ou seja, transferindose o conhecimento para situações novas e aplicando-as nessas novas realidades. Corresponderia a uma verdadeira aprendizagem para a ação prática, o exercício da cidadania, em que a educação dialógico-problematizadora consegue conduzir a um maior empowerment (SAITO, 2001; SANTOS et al., 2005), tanto no plano individual (aquisição de conhecimento científico-tecnológico) como no plano coletivo (aumento no poder de intervenção para transformar a realidade com base no conhecimento científico-tecnológico adquirido). Porém na condição histórico-evolutiva de sermos Homo sapiens, não podemos nos reduzir a mera reprodução de conhecimento, seja pelo canal da imagem-comunicação, seja pelo canal da cognição-aprendizagem. Essencial se faz a construção de oportunidades de intervenção que mesclem estímulos diretos e estímulos mediatizados-neurodidáticos, capazes de construir seres sábios e com posturas de valores sustentáveis de proteção 
e conservação ambiental, que exercitem a autonomia para serem felizes e capazes de realizarem escolhas saudáveis e responsáveis.(MARQUES, 1999).

Sugerimos, adicionalmente, que se reflita sobre a possibilidade de o FICAANIMADO passar a ser incorporado pelo Festival na mostra competitiva. Isso talvez pudesse promover a seleção pelo júri dos critérios de excelência que caracterizam a seleção de filmes do festival há mais de uma década.

\section{Agradecimentos}

Agradecemos à coordenação do XI Festival Internacional de Cinema e Video Ambiental - FICA e ao Prof. Laerte Guimarães Ferreira pela oportunidade de realização do mini curso, a este último ainda pelo incentivo à sistematização da experiência, e a Denise de Oliveira, do CNPq, pela gentil revisão do manuscrito e valiosas sugestões.

\section{REFERÊNCIAS}

BECKER, F. A origem do conhecimento e a aprendizagem escolar. Porto Alegre: Artmed, 2003. $116 \mathrm{p}$.

FONSECA, V. Cognição, Neuropsicologia e Aprendizagem. Petrópolis: Vozes, 2009.184p.

FREIRE, P. Educação como prática da liberdade. Rio de Janeiro: Paz e Terra,1967. $150 p$.

. Extensão ou comunicação? Rio de Janeiro: Paz e Terra,1970. 93p.

Pedagogia do Oprimido. Rio de Janeiro: Paz e Terra, 1987. 184p.

Pedagogia da esperança: Um reencontro com a Pedagogia do Oprimido. Rio de Janeiro: Paz e Terra, 2003. 245p.

FRIEDMAN, J. Empowerment: the Politics of the Alternative Development. Cambridge: Blackwell Publishers, 1992. 196p.

MARQUES, K. Reinventando a criança interna. Goiânia: Vieira,1999. 167p.

Caixas Lúdicas de Avaliação da Aprendizagem - Padronização de Instrumentos. In: CONGRESSO INTERNACIONAL "SER PROFESSOR DE EDUCAÇÃO ESPECIAL", 1., 2009. Anais... Lisboa: Associação Nacional de Docentes de Educação Especial, 2009. 11p.

PINTO, C. Empowerment: uma prática de serviço social. In: BARATA, O . S. (Org.). Política Social. Lisboa: ISCSP,1988. p. 245-277.

PORTILHO, E. Como se aprende? Estratégias, Estilos e Metacognição. Rio de Janeiro: Wak, 2009. 164p.

RELVAS, M.P. Neurociências e educação. Rio de Janeiro: Wak, 2009. 149p.

SAITO, C.H. Por que investigação-ação, empowerment e as idéias de Paulo Freire se integram? In: MION, R.A. E SAITO, C.H. (Org.). Investigação-Ação: mudando o trabalho de formar professores. Ponta Grossa: Gráfica Planeta, 2001. p.126-135.

Política Nacional de Educação Ambiental e construção da cidadania: desafios contemporâneos. In: RUSCHEINSKY, A. (Eds.) Educação Ambiental: Abordagens Múltiplas. Porto Alegre: Artmed, 2002. p. 47-60.

SAITO, C.H. ;ALMEIDA, L.E. Conservação da Biodiversidade e a valorização do componente educacional. Floresta e Ambiente, v. 13, p.66-74, 2006. 
SAITO, C.H. ; BASTOS, F.P. ; ABEGG, I. Temáticas ambientais e biomas brasileiros: análise dos trabalhos de pesquisa em Educação em Ciências em eventos científicos nacionais nos últimos cinco anos. Revista Eletrônica do Mestrado em Educação Ambiental, v. 17, p. 167-177, 2006.

Teorias-guia educacionais da produção dos materiais didáticos Teoriasguia educacionais da produção dos materiais didáticos para a transversalidade curricular do meio ambiente do MMA. Revista Iberoamericana de Educación (Online), v. 45, p. 1-10, 2008.

SANTOS, I.A. et al. The Centrality of the mediation concept in the participatory management of water. Canadian Journal of Environmental Education, Lakehead University, Ontario, v. 10, p. 180-194, 2005.

1 Biólogo, Doutor em Geografia. Universidade de Brasília, Departamento de Ecologia: Cx.Postal 04457 CEP 70904-970, Brasília-DF, Brasil. Email: <carlos.saito@pq.cnpq.br>; <carlos.h.saito@ hotmail.com>.

2 Psicopedagoga, Doutora em Ciências da Educação. Espaço Interativo Aprender a Aprender: Rua 231 qda 10 lt 55 St Coimbra, CEP 74535-220, Goiânia - GO, Brasil. Email:<kelleymarques@hotmail. com>.

3 Situações existenciais típicas: são situações existenciais dos grupos (situações que se relacionam diretamente aos grupos), com quem iremos trabalhar educacionalmente, ou seja, procuramos chegar aos problemas concretos vividos no cotidiano pelas pessoas que vivem nestes lugares

4 Codificação de situações-problema: apresentação, normalmente na forma de imagens (fotos, por exemplo) a realidade concreta. 